\title{
Ioannis Calvini, Varia. Volumen I (Congrégations et Disputations)
}

\section{Michele Mastroianni}

\section{Q OpenEdition}

1 Journals

\section{Edizione digitale}

URL: http://journals.openedition.org/studifrancesi/405

DOI: $10.4000 /$ studifrancesi.405

ISSN: 2421-5856

\section{Editore}

Rosenberg \& Sellier

\section{Edizione cartacea}

Data di pubblicazione: 1 aprile 2015

Paginazione: 136

ISSN: 0039-2944

\section{Notizia bibliografica digitale}

Michele Mastroianni, « Ioannis Calvini, Varia. Volumen I (Congrégations et Disputations) », Studi Francesi

[Online], 175 (LIX | I) | 2015, online dal 01 avril 2015, consultato il 18 septembre 2020. URL : http:// journals.openedition.org/studifrancesi/405; DOI : https://doi.org/10.4000/studifrancesi.405

Questo documento è stato generato automaticamente il 18 settembre 2020.

\section{(c) (i) (9)}

Studi Francesi è distribuita con Licenza Creative Commons Attribuzione - Non commerciale - Non opere derivate 4.0 Internazionale. 


\title{
Ioannis Calvini, Varia. Volumen I (Congrégations et Disputations)
}

\author{
Michele Mastroianni
}

\section{NOTIZIA}

IOANNIS CALVINI, Varia. Volumen I (Congrégations et Disputations), edidit Erik Alexander DE BOER, Genève, Droz, 2014, pp. xxv-491.

1 A Ginevra con il termine congrégation si indicava la riunione di pastori, insieme ad altri membri della Chiesa, che si teneva la mattina del venerdì dopo il culto mattutino $\mathrm{e}$ nella quale su di un testo biblico o su di un problema teologico dibattuto si faceva un' exposition da parte di chi presiedeva la riunione, seguita da interventi dei presenti. Con il termine Congrégation vengono anche designati i testi (giunti a noi nella trascrizione di uno scrivano). Tra il 1549 e il 1564, anno della morte di Calvino, dovrebbero essersi tenute oltre settecento congrégations, di cui moderatore sarebbe stato Calvino, ma ci sono pervenuti soltanto una trentina di testi trascritti. Nelle Congrégations, qui pubblicate, abbiamo sia expositions del grande riformatore sia sue addizioni, come pure abbiamo interventi di altri membri delle assemblee. Si tratta quindi di una testimonianza eccezionale non solo del pensiero e dell'attività di Calvino predicatore, ma anche della ricezione del suo pensiero da parte della Chiesa ginevrina e della riflessione teologica comunitaria. L'edizione di E.A. de Boer offre l'insieme di questi testi, che in genere offrono commenti biblici (su brani di Giuda, di Giovanni, dell'Esodo, dei Galati, di Giosué, di Isaia) ma anche esposizioni e dibattiti dottrinali, come l'importante Congrégation sur l'election nouvelle de Dieu che affronta un tema centrale della teologia calviniana e soprattutto ci informa di un débat che fece scalpore, quello contro Jérôme Bolsec. Queste Congrégations hanno anche un grande interesse sul piano linguistico, sia per essere frutto di interventi in parte caratterizzati dall'immediatezza sia per essere risultato di trascrizioni ad opera di scrivani uditori, il che pone una serie di problemi filologici illustrati nell'introduzione alla presente edizione. Ogni 
Congrégation è anche preceduta da una limpida prefazione che commenta e inquadra i testi. 